\title{
Access and interconnection pricing: how efficient is the "efficient component pricing rule"?
}

BY NICHOLAS ECONOMIDES* and LAWRENCE J. WHITE*

\section{Introduction}

The question of how a monopolist owner of a bottleneck facility should set the price for access to the facility by an entrant or rival supplier of a complementary component continues to be an interesting question for theory and policy. ${ }^{1}$ This question is often

* Stern School of Business, New York University, NY.

AUTHORS' NOTE: The authors thank Timothy Brennan for helpful comments on an earlier draft of this article. The authors also thank the participants at the CEPR/CREST-LEI conference on Mobile Telephony, the Utilities Regulation Network conference at the Catholic University of Milan, and of the 1995 Annual National Conference of Economic Research in France for helpful comments and suggestions.

1 See William J. Baumol, Some Subtle Issues in Railroad Deregulation, 10 InT. J. Trans. ECoN. 341 (1983); Telecom Corporation of New Zealand and Others v. Clear Communications Ltd, Privy Council, House of Lords, U.K. (1994), Curtis M. Grimm \& Robert G. Harris, Vertical Foreclosure in the Rail Freight Industry: Economic Analysis and Policy Implications, 5 ICC PRACT. J. 508 (1983); Henry McFarland, Railroad - 1995 by Federal Legal Publications, Inc. 
framed in terms of a regulated monopolist vis-a-vis an entrant or rival in an unregulated complementary activity; but the issue can also arise in the antitrust context of an unregulated "essential facility" monopolist that is vertically integrated into a complementary upstream or downstream activity in which one or more other producers are present (or may enter). ${ }^{2}$

As technological changes and legal-regulatory changes have created more opportunities for competition in activities that are complementary to a still-regulated bottleneck facility, the policy relevance of the access pricing question has been heightened. Familiar examples include:

Local telephone service entrants who must route calls to and from the customers of the incumbent (bottleneck monopoly) provider through the incumbent's switches.

Long-distance telephone service providers who must access customers via the local (monopoly) switched network; this example extends immediately to other providers of complementary telephone services. In these instances, the local monopolist is usually also an actual or potential provider of the long-distance and other complementary services.

Competitive Access: An Economic Analysis, mimeo (1985); Nicholas Economides \& Glenn Woroch, Benefits and Pitfalls of Network Interconnection, mimeo (1992); WILIAM J. BAUMOL \& GREGORY SIDAK, TOWARD COMPETITION IN LOCAL TELEPHONY (1994); William J. Baumol \& Gregory Sidak, The Pricing of Inputs Sold to Competitors, 11 Y ALE J. REg. 171 (1994); Alfred E. Kabn \& William E. Taylor, The Pricing of Inputs Sold to Competitors: Comment, 11 YALE J. REG. 225 (1994); Henry Ergas \& Eric Ralph, Pricing Interconnection: Is the Baumol-Willig Rule the Answer? mimeo (1994); Mark Armstrong \& Chris Doyle, Interconnection and the Effects of Entry, mimeo (1994); Jean-Jacques Laffont \& Jean Tirole, Access Pricing and Competition, 38 Euro. ECON. REv. 1673 (1994); and Mark Armstrong \& John Vickers, The Predatory Access Pricing Problem, mimeo (1994).

2 For recent discussions of the essential facilities doctrine, see Gregory Werden, The Law and Economics of the Essential Facilities Doctrine, 32 Sr. LouIS U. L. REv. 432 (1987); James Ratner, Should There Be an Essential Facilities Doctrine?, 21 U. C., DAvIs L. REv. 327 (1988); and David Reiffen \& Andrew N. Kleit, Terminal Railroad Revisited: Foreclosure of an Essential Facility or Simply Horizontal Monopoly?, 33 J. L. \& ECoN. 419 (1990). 
$E C P R: 559$

Generators of electricity who wish to sell to ultimate customer-users but who can reach those customers only through a local (monopoly) distribution network (and possibly also a monopoly transmission system); again the local monopoly distributor typically also owns generating facilities.

Sellers of natural gas who similarly wish to sell to ultimate customerusers but who can reach those customers only through monopoly gas transmission pipelines and/or a monopoly local distribution network.

In addition, eased merger standards in some sectors (e.g., railroads) have created local monopoly bottlenecks that generate an access problem for competing firms that provide complementary components or services.

A widely discussed "rule" for the pricing of access to these bottleneck facilities was originally proposed by $\mathrm{Baumol}^{3}$ and has recently been popularized by Baumol and Sidak; 4 it is frequently described as the "efficient component pricing rule" (ECPR), which is the terminology that we will use in our subsequent discussion. The ECPR states that the appropriate access charge by the bottleneck monopolist to the providers (actual or potential) of a complementary component or service, which the monopolist also produces (and thus the other providers are rivals to the monopolist), is a fee equal to monopolist's opportunity costs of providing the access, including any foregone revenues from a concomitant reduction in the monopolist's sales of the complementary component.

The ECPR has a seductive logic: It insures that a rival producer of the complementary component can provide service only if that producer is at least as efficient as the monopolist in the production of the complementary component; i.e., the ECPR insures that production will not be diverted to an inefficient producer.

It is now well established that the ECPR holds as a first-best pricing principle only if a stringent set of assumptions holds: 5 the

3 See Baumol, supra note 1.

4 See Baumol \& Sidak, supra note 1, and BAUMol \& SmaK, supra note 1 .

5 See Laffont \& Tirole, supra note 1. 
monopolist's price for the complementary service has been based on a marginal-cost pricing rule; the monopolist's and rival producer's components are perfect substitutes; the production technology of the component experiences constant returns to scale; the rival producer has no market power; and the monopolist's marginal cost of production of the component can be accurately observed.

In this article, we will examine the consequences of relaxing some of these assumptions. We focus special attention on the case where the monopolist has been charging a price for the complementary component that is above all relevant marginal costs. As we show, in this case the ECPR's exclusion of inefficient rivals may be socially harmful; the market presence of even an inefficient rival could bring net social benefits, by causing the price to fall sufficiently so that the net gain to consumers (the reduction in the deadweight loss "triangle") would exceed the inefficiency costs of the rival's production.

To help readers with the analysis that follows, we offer figure 1 as a schematic of the framework that we are presenting. We describe our framework in terms of telephone services (but the other examples mentioned above are easily applied): The monopolist owns the switch at location $B$ and provides local telephone service between and among customers at points $A_{1}, A_{2}, A_{3}$, etc. All of the local customers must use the monopolist's switch to complete (connect) their local calls and to gain access to other (complementary) services, such as long distance.

The same firm that provides the monopoly local service also provides service from points $A_{1}, A_{2}, A_{3}$, etc., through switch $B$ to point $C$. This service could be "long distance"; or it could be additional "local" service to additional customers; or it could be some other complementary service (e.g., access to an information database) that requires the use of switch $B$. We will describe this $\mathrm{ABC}$ (or $\mathrm{CBA}^{6}$ ) service simply as "through service." There is at

6 For a discussion of one-way networks and two-way networks, see Nicholas Economides \& Lawrence J. White, Networks and Compatibility: Implications for Antitrust, 38 EURO. ECON. REV. 651 (1994). In two-way networks, such as telephone or rail systems, $A B C$ and CBA are distinct 
$E C P R: 561$

Figure 1

Interconnection to a Bottleneck. (The links owned by the monopolist are drawn in bold)

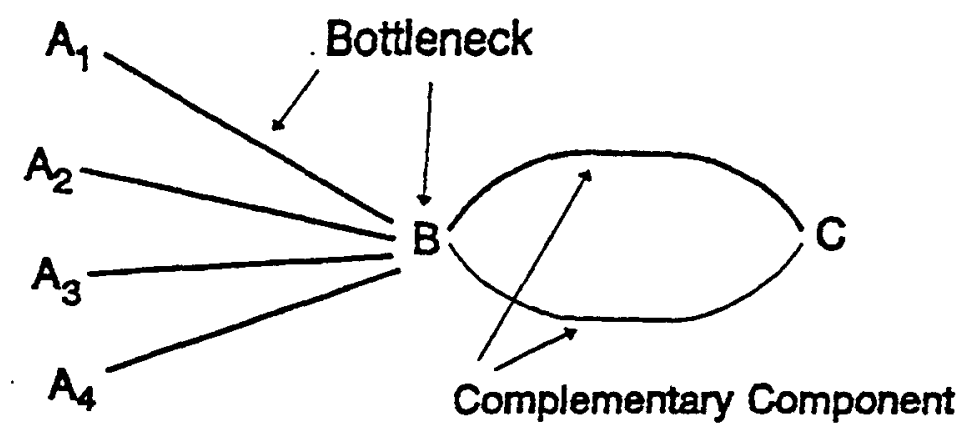

least one other potential or actual provider of the service to point C. This rival requires access to (through) the switch in order to provide the $A_{1}, A_{2}, A_{3}$, etc., customers with the "through" service $A B C$ (and $C B A$ ). We assume, however, that the rival owns only facilities between $B C$, while the monopolist owns the switch $B$ as well as its own facilities between $B C$ (drawn in bold) and the links $A_{1} B, A_{2} B$, etc. In the language of the ECPR, the switch $B$ is the monopoly bottleneck ${ }^{7}$ and segment $B C$ is the complementary component.

The early sections of the article will assume the following:

The monopolist and the rival offer identical service over segment BC.

Service between $B$ and $C$ has value only as part of the through service $A B C$ or $C B A$.

Constant returns to scale production technology applies to the production of service between B and C.8

goods or services. In a one-way network (such as an electricity grid), only one of these combinations is meaningful.

7 The segments between $B$ and $A_{1}, A_{2}, A_{3}$, etc., may or may not also be part of the monopoly bottleneck.

8 We will make the standard economics assumption that normal, competitive profit levels will be a component of the cost concepts discussed later in the article. 
562 : The antitrust bulletin

The monopolist is able to charge prices for local service to its local customers that are sufficient to cover all of its costs of providing that local service (i.e., sufficient to cover the costs of providing links $A B$ and the costs of the switch).

The price of the through service $A B C$ (and $C B A$ ) is not subject to direct price regulation.

The consumer demands for local service and through service exhibit normal properties; e.g., the prices that consumers are willing to pay are indicative of the welfare or satisfaction that they receive from the services; at lower prices consumers want to buy more of the services, etc.

In later sections of the article we will explore the consequences of modifying some of these assumptions.

The remainder of this article will proceed as follows: section II will lay out the structure of the basic ECPR and explore its logic. Section III will examine the consequences of the monopolist's price embodying a monopoly overcharge. Section IV will analyze the consequences of the components' not being perfect substitutes. Section $V$ discusses the case when economies of scale are present. And section VI will offer a brief conclusion.

\section{The logic of the efficient component pricing rule}

The logic of the ECPR is readily demonstrated through a simple numerical example:

Suppose that the monopolist charges a price of $\$ 0.10$ for through service $A B C$ (or $C B A$ ). Suppose further that the monopolist's marginal costs of providing this service are $\$ 0.02$ for segment $B C$ and $\$ 0.05$ for segment $A B$ (including the relevant marginal costs of the switch $B$ ). The ECPR simply states that the appropriate price or fee for the monopolist to charge to the rival for access to switch $B$ (and for providing the connecting service $A B)$ is $\$ 0.08$ : The $\$ 0.05$ of marginal costs relevant to segment $\mathrm{AB}$ plus the foregone net revenue of $\$ 0.03$ that the monopolist loses when the rival provides the through service in lieu of the monopolist. 
If the rival is being charged a fee of $\$ 0.08$ for access, and the monopolist is charging $\$ 0.10$ as its price to customers for through service, then the rival will be able to offer through service without incurring losses only if its marginal costs for segment $B C$ are at or below $\$ 0.02$-i.e., at or below the marginal costs (over $\mathrm{BC}$ ) of the monopolist.

Thus, the ECPR insures that the rival enters and produces in the market only if its costs are no greater than those of the monopolist; inefficient diversion of production away from the monopolist will not occur as a consequence of the presence of the rival in the market. Further, if all of the conditions mentioned in the Introduction (including pricing by the monopolist at marginal cost) are satisfied, the ECPR will provide global efficiency.

III. The monopolist initially has market power in the complementary component

The previous section made no explicit assumption as to the basis for the monopolist's price for the through service. We now explicitly assume that in the absence of the rival the monopolist is able to charge the full profit-maximizing monopoly price for the through service. 9 In turn, this maximizing behavior implies that the monopolist's markup over marginal costs is directly related to those marginal costs and to the elasticity of demand for the service.

This monopoly outcome can be portrayed in a familiar geometric diagram, provided in figure 2. With demand curve (DD) for through service and constant marginal costs $(\mathrm{MC})$ for the monopo-

9 Baumol \& Sidak, supra note 1 , and BAUMOL \& SIDAK, supra note 1, briefly acknowledge the possibility that the monopolist's price for the complementary component (or, in our case, through service) might reflect market power and not be based on a marginal-cost pricing rule, and they acknowledge that this possibility would mean that the optimal properties of the ECPR would not hold; but they nevertheless devote virtually all of their analysis and discussion to the case where market power is absent. Kahn \& Taylor, supra note 1, note this brief acknowledgement and the possibilities that might follow from market power, but they do not fully pursue the point. 
564 : The antitrust bulletin

list, the profit-maximizing monopolist would charge a price of $P_{M}$ and produce a quantity $\mathrm{Q}_{\mathrm{M}}$. (This can be compared to the price $\mathrm{P}_{\mathrm{C}}$ and quantity $Q_{C}$ that would be yielded by a marginal-cost pricing regime.) The monopolist's markup over marginal costs is the vertical distance between $P_{M}$ and $M C$.

Figure 2

Monopoly Pricing and Deadweight Loss

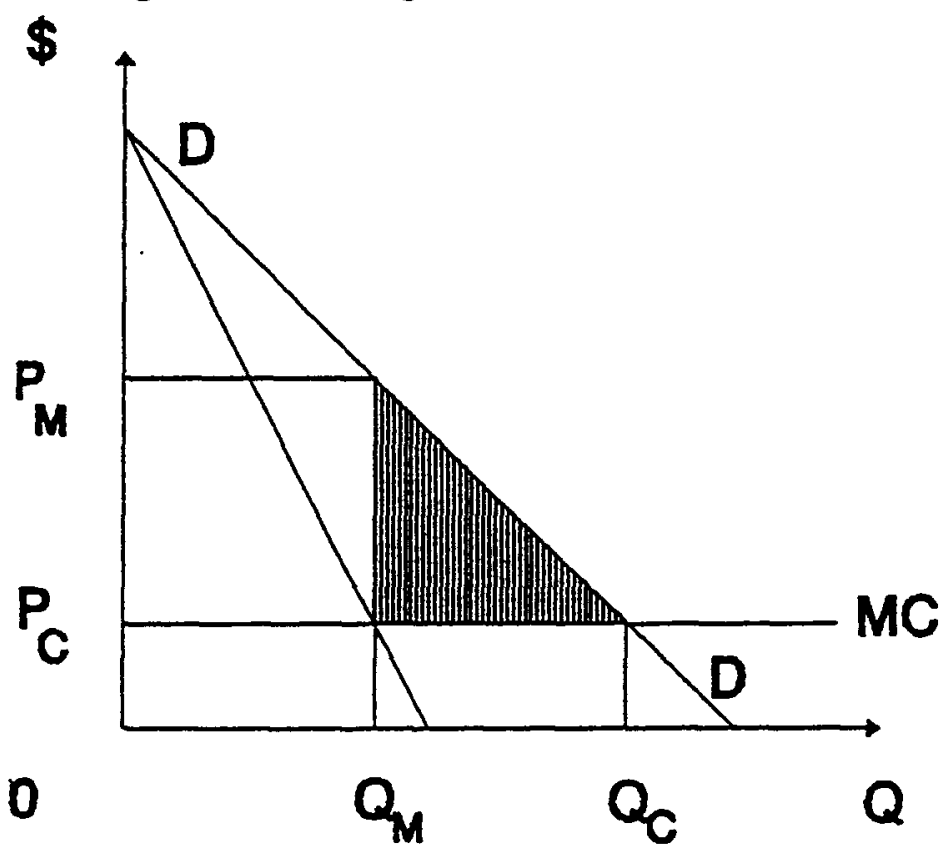

The ECPR described in the previous section would prescribe that the monopolist's markup or overcharge be a component of the access fee. Thus, the ECPR would deter inefficient rivals (those with marginal costs that are higher than the monopolist's MC) and prevent inefficient production. But the ECPR also protects the monopolist from any competitive challenge by these rivals and thus protects the monopolist's profits; and the ECPR preserves the allocative or consumption inefficiency that results from the monopolist's excessively high price for through service. The social loss of the protected monopoly is usually calculated as the "deadweight loss triangle" (DWL) shown as the shaded area in figure 2: The loss of consumers' surplus by demanders who are shut out of the market by the monopolist's high price. 
It is easy to see that, if the monopolist has market power in the market for the complementary component, the ECPR is the monopolist's profit-maximizing access fee when the rival is less efficient than the monopolist, since the ECPR precludes entry and allows the monopolist to continue to reap its full monopoly rents. ${ }^{10}$

\section{A. Production by a less efficient rival could yield net social gains}

If the monopolist were required (e.g., by regulation) to levy a lower access fee, a less efficient rival could begin production. But it is nevertheless possible that social welfare would increase, because the diminished DWL from the lower price that could accompany entry could more than compensate for the social cost of the rival's inefficient production." The magnitudes of the price decrease and the rival's inefficiency, and also the fractions of postentry production that the rival captures, will be crucial to this determination.

1. BERTRAND COMPETITION To show that entry by even an inefficient rival could yield socially beneficial results, we assume that the monopolist is restricted (e.g., by regulation) to levying an access fee that is equal only to the actual marginal costs of access (i.e., the marginal costs of segment $A B$, including the switch). We further assume that an entrant to segment $B C$ has higher costs than the monopolist by an amount $t$, where $0 \leq t \leq\left(P_{M}-M C\right)$.

Suppose that in response to the prospect or actuality of entry, the monopolist practices limit pricing: It sets the price $\left(P_{J}\right)$ at which both producers sell at a level that is just equal to the entrant's costs. Under this pricing regime the entrant will capture some share $\theta(0 \leq \theta \leq 1.0)$ of the joint market sales $\left(Q_{J}\right)$ of through service.

10 The profit-maximizing access fee when the rival is more efficient than the monopolist is discussed below in the text.

11 The analysis that follows in the text is an adaptation, in reverse form, of the approach of Oliver E. Williamson, Economics as an Antitrust Defense: The Welfare Tradeoffs, 58 AM. Econ. REv. 18 (1968). 


\section{6 : The antitrust bulletin}

In the terms of figure 3 , consider the change from pure monopoly (point $\mathrm{X}$ ) to limit pricing (at point $\mathrm{Y}$ ). The approximate social gain from this change is a combination of a "triangle" gain in consumers' surplus $\left(1 / 2 \Delta P \cdot \Delta Q=1 / 2\left[P_{M}-P_{J}\right] \cdot\left[Q_{J}-Q_{M}\right]\right)$, represented by area $X Y Z$, and a "rectangle" gain in producers' surplus ( $t \cdot \Delta Q=t \cdot\left[Q_{J}-Q_{M}\right]$ ), represented by area $Z Y R W$; the combined areas are the trapezoid XYRW. This gain is offset by the production inefficiency: the entrant's cost disadvantage multiplied by the entrant's production volume, or $t \theta Q_{J}$, which represents some fraction $(\theta)$ of the rectangle $P_{J} Y_{R P}$. The net gain can be either positive or negative, depending on the values of $t, \theta$, and the elasticity of demand (e).

\section{Figure 3}

Dead Weight Gain and Production Inefficiency

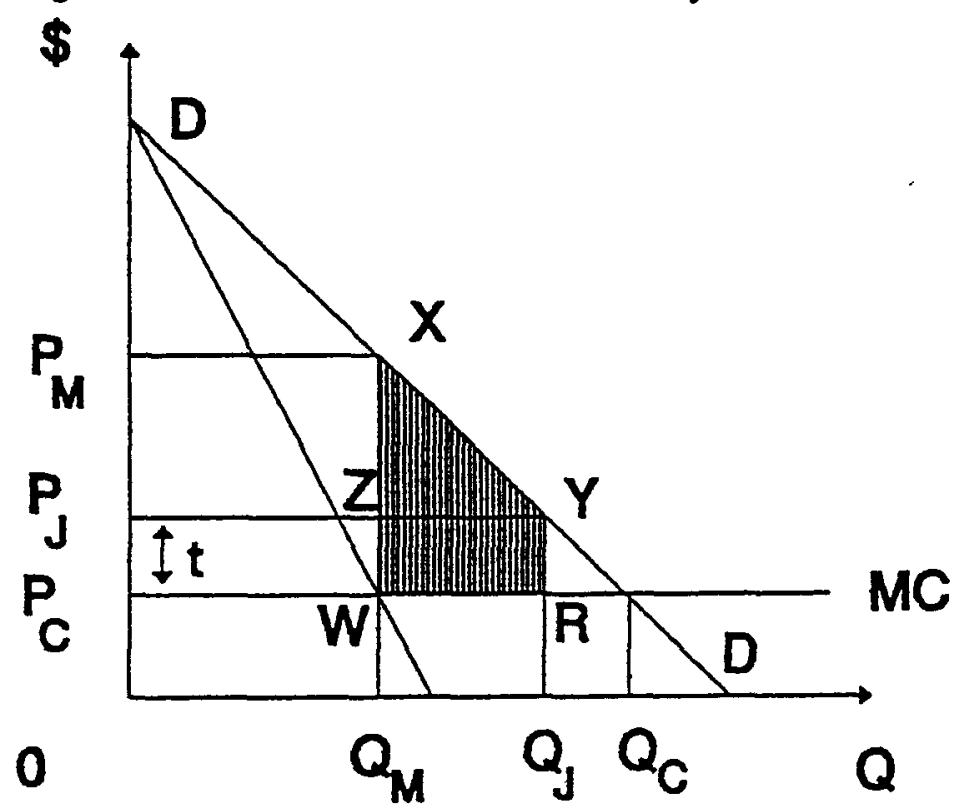

For specified values of $\theta$ and $e$, it is possible to find (solve for) a maximum level of cost disadvantage $\left(t^{*}\right)$ that just eliminates the net social gain. 12 Then, for the specified values of $\theta$ and $e$, entry by a firm with cost disadvantage $t, t<t^{*}$, will yield a social gain. In table 1 we provide the $t^{*}$ values associated with a range of

12 Appendix A provides the calculations that yield $t^{*}$. 
plausible values for e and for some benchmark values of $\theta$ : $\theta=0$ (the mere threat of entry causes the monopolist to practice limit pricing); $\theta=0.5$ (a Bertrand equal-sharing of the market between the monopolist and the rival); and $\theta=1.0$ (the "worst" case, in which the less efficient rival somehow captures the entire market). As can be seen, for these "realistic" elasticity values, a rival may experience a substantial cost disadvantage and still be the vehicle for a net social welfare improvement. These results are even more striking if the rival's cost disadvantage is expressed as a percentage of the monopoly's profit-maximizing price differential (or profit margin).

\section{Table 1}

Matrix of $t^{*}$ Values for Bertrand Competition Elasticity e

\begin{tabular}{llll}
$\theta$ & \multicolumn{1}{c}{2.0} & \multicolumn{1}{c}{3.0} & \multicolumn{1}{c}{4.0} \\
0 & $1.00^{2}(100 \%)$ & $0.50^{*}(100 \%)$ & $0.33^{2}(100 \%)$ \\
0.50 & $0.67(67 \%)$ & $0.33(65 \%)$ & $0.21(65 \%)$ \\
1.0 & $0.50(50 \%)$ & $0.24(47 \%)$ & $0.15(46 \%)$
\end{tabular}

- Profit maximizing monopoly markup over marginal cost (profit margin).

NOTE: The numbers in parentheses represent $t^{*}$ expressed as a percentage of the maximum monopoly markup.

2. COURNOT DUOPOLY We have thus far performed our analysis on the basis of an assumption of a "tough" pricing environment between the monopolist and the rival: Bertrand-like limit pricing by the monopolist. More accommodating behavior between the monopolist and the rival would yield higher prices for any $t$ by the rival and hence a lesser likelihood of a social welfare gain; at the limit, if both the monopolist and rival sell at the monopoly price $\left(P_{M}\right)$, with the monopolist ceding to the entrant some share $\theta$ of the monopoly volume $\left(\mathrm{Q}_{\mathrm{M}}\right)$, then the outcome yields only the social loss $\left(t \theta Q_{M}\right)$ due to the inefficient production of the entrant.

As an example of an intermediate level of pricing toughness, we assume that the competition between the incumbent and the entrant is a-la-Coumot; i.e., each producer adjusts its own produc- 
tion quantity on the assumption that the other producer's quantity will remain unchanged. If a linear demand curve is used for illustration, then, similar to our Bertrand demonstration, we can solve for a $t^{*}$, such that all $t<t^{*}$ will yield a net social gain. ${ }^{13}$ For this Cournot conjecture by the producers, the market share of the entrant $(\theta)$ is endogenous, with $\theta \simeq 0.31$ (i.e., a market share of $31 \%$ ) at $t=t^{*}$ and $\theta=0.50$ at $t=0$. Table 2 shows the critical values of $t^{*}$ for the same "realistic" values of e that were provided in our Bertrand case. As can be seen in a comparison of table 2 with table 1, the $t^{*}$ values for this Cournot case are smaller than for the Bertrand case, because Cournot competition implies higher prices and a substantial market share for the less efficient rival. Still, again, entry by a firm with a nontrivial production cost disadvantage relative to the monopolist can result in a net social gain.

Table 2

Values of $t^{*}$ for Cournot Competition

$\begin{array}{ccc} & \text { Elasticity e } \\ 2.0 & 3.0 & 4.0 \\ 0.29(29 \%) & 0.17(33 \%) & 0.12(35 \%)\end{array}$

NOTE: The numbers in parentheses represent $t^{*}$ expressed as a percentage of the maximum monopoly markup.

We also note that if more than one rival is present in the market, so that there is competition among a number of firms, the equilibrium price is likely to be closer to the Bertrand limit pricing case, and definitely lower than for the Cournot duopoly. Thus, in the presence of more than one rival, the welfare gain from the competition that they bring is more likely to be positive.

3. A SUMMING UP The ECPR's apparent strength-its exclusion of an inefficient rival-may also be its drawback when the monopolist is charging high prices (in excess of all relevant marginal costs) for the complementary component. In that case, the exclusion of the rival also prevents the possibility of a lower price for the complementary component, with its attendant reduc-

13 Appendix B shows the steps that are required to solve the Cournot competition problem and generate a solution for $t^{*}$. 
tion in consumers' deadweight loss; the net social gain from the rival's presence could be positive. The extent of the price decrease, the size of the rival's cost advantage, and the rival's equilibrium market share are the key determinants of whether the rival's presence in the market would be beneficial. In turn, the oligopolistic conjecture held by the two producers and the market elasticity of demand will influence these magnitudes. At one extreme, if the monopolist practices Bertrand-like limit pricing, the presence of a rival with even a substantial cost disadvantage can be socially beneficial. At the other extreme, if the monopolist and the rival jointly maintain the monopolist's previous high price (with the monopolist simply ceding some market share to the rival), then any market presence by a less efficient rival will be socially deleterious. Cournot duopoly yields an equilibrium price that is between these extremes, with an endogenously determined market share for the rival. Even with Cournot duopoly, nontrivial cost inefficiencies by the rival are consistent with a net social gain.

Further reflection on the ECPR reveals both a greater universality to its logic but also a greater universality to the critique that we have-just offered. ${ }^{14}$ Though the ECPR is usually presented in terms of access to a bottleneck facility, its logic extends to any entry by any rival firm into any market where there is an incumbent. If the sole goal of social policy is to prevent inefficient production by an entrant from displacing more efficient production by the incumbent, then the ECPR principle-the entrant must reimburse incumbent for the latter's opportunity costs, including foregone net revenues-will achieve that goal. But, if the incumbent is exercising market power, then the use of the ECPR will also protect the incumbent and preserve its market power against the competitive erosion of prices and margins that even less efficient rivals could bring. If the ECPR is placed in this context, the luster of its rationale tarnishes rapidly.

An "entry tax" that required market entrants generally to reimburse incumbents for their foregone net revenues would quickly

14 We are grateful to Timothy Brennan for pointing this out to us. 
be seen as a protective and anticompetitive device and would likely receive little support from policy-oriented economists, despite any claims that the tax would preclude inefficient production. The ECPR is just this type of entry tax.

\section{B. The ECPR's harm when the rival is more efficient than the monopolist}

The previous section only addressed instances where the rival is less efficient than the monopolist in the production of the complementary component. Even in those circumstances, as we demonstrated, the net effect of the ECPR could be harmful.

If the rival is more efficient than the monopolist, then the monopolist's profit-maximizing strategy would generally ${ }^{15}$ be to cede production of the complementary component to the more efficient rival and to reap its monopoly profits through an appropriate access fee. ${ }^{16}$ This access fee could be either greater or less than the ECPR, depending on the shape of the demand curve for through service.

Thus, for this case the presence of the ECPR would allow production to shift to the more efficient producer. But the ECPR access fee would mean that consumers would continue to endure the inefficiencies of the artificially high price for through service. And the divergence of the ECPR from the monopolist's profitmaximizing access fee could imply either further distortion (if the ECPR is higher than the profit-maximizing fee) or a lessening of distortion (if the ECPR is lower). ${ }^{17}$

15 We discuss exceptions below in the text.

16 By ceding all production of the complementary component to the rival, the monopolist might be creating problems of vertical supplier-customer relationships, with the consequent problems of double marginalization, etc. But the monopolist's ability to self-supply the complementary component at its own marginal cost would put a limit on the extent to which the rival could attempt to exploit that position.

17 The discussion in this section thus indicates that a more complete "Williamson" type analysis should also include the possibility that a more efficient rival might enter, and the absence of the ECPR would 
$E C P R: 571$

IV. The complementary components of the monopolist and the rival are imperfect substitutes

We now assume that the complementary components of the monopolist and the rival are imperfect substitutes; i.e., the monopolist and the rival compete in offering through service, but their service offerings are not identical. To continue with our telephone example, the rival's through service (e.g., long-distance service) might involve faster connections or a higher percentage of completed calls, but also an increased level of static on the line, as compared with the monopolist's long-distance service.

The introduction of imperfect substitutes immediately calls into question the meaning of any comparisons of production cost efficiency between the two components. Since the two components now have different attributes and satisfy (somewhat) different demands, comparisons of their unit costs have little or no meaning. It is rarely interesting or analytically worthwhile to compare the "unit" costs of an apple producer and an orange producer.

Even if the units of the two complementary components are somehow comparable, the analog of the ECPR's consequences for the perfect substitutes case is that the imposition of the ECPR to the rival's imperfect substitute would exclude a rival's production entirely when there was no customer with a willingness to pay for the rival's service such that the rival's price-less-costs margin could exceed the ECPR access fee. Unless the ECPR were based on a marginal-cost pricing rule (and thus in this case there were no customers of the rival's service whose willingness to pay would cover all relevant marginal costs), the exclusion of these "modest" willingness-to-pay customers by the ECPR access fee would not serve the goal of promoting production efficiency. ${ }^{18}$

If we move away from a production efficiency criterion, then an access fee might serve some other purpose-say, maximize the

mean that consumers would enjoy the full benefits of the lower price brought by the entrant.

18 See also Laffont \& Tirole, supra note 1; Armstrong \& Doyle, supra note 1; and Armstrong \& Vickers, supra note 1. 
monopolist's profits, or help solve a Ramsey pricing problem if inadequate revenues can be earned from the monopolist's bottleneck service customers. Only by chance would the ECPR access fee be the solution to either of these problems.

\section{Economies of scale}

In the presence of economies of scale in the production of the bottleneck service and/or the complementary component, the ECPR is again unlikely to provide a first-best pricing outcome.

\section{A. Ramsey pricing}

Suppose, contrary to our earlier assumption, that the monopolist is unable to earn sufficient revenue in the bottleneck market to cover its costs (e.g., because of economies of scale). In the absence of any other source of funds, the regulator must extract a contribution from the customers of through service. To maximize social welfare, the regulator must solve a Ramsey problem: select the set of prices for local service and through service that maximizes consumers' surplus while also covering the costs of those services. The resulting Ramsey price for through service would involve, in essence, an excise tax that is levied on through service. If the monopolist is the low cost producer of the complementary component, the monopolist "pays the excise tax to itself"; if the rival is the low cost producer, the rival pays the tax to the monopolist as an access fee. To insure optimality, the regulator would have to regulate directly the excise tax and the resulting price of through service. Only by chance would the ECPR access fee be identical to the Ramsey excise tax. ${ }^{19}$

\section{B. The monopolist may use the ECPR to exclude a more efficient rival}

There are at least two circumstances in which the monopolist's profit-maximizing strategy is to exclude the rival, even when the

19 See Laffont \& Tirole, supra note 1; Armstrong \& Doyle, supra note 1 ; and Armstrong \& Vickers, supra note 1 . 
rival is more efficient at producing the complementary component, rather than cede production to the rival. In both instances, the monopolist would find it worthwhile to understate its own marginal costs of production of the complementary component and then impose a heightened ECPR on the rival.

In the first case, we now assume either that segment $B C$ is a separate stand-alone market (as would be true for local railroad freight hauling) or that it is a complementary component for through service to (or from) points $D, E, F$, etc., that are served by other firms (but not by the original monopolist). We also depart from our assumption of constant returns to scale in the production of the complementary component and instead assume that there are economies of scale. If the monopolist can exclude the (more efficient) rival from offering through service in the $A B C$ market, this could sufficiently deprive the rival of the benefits of scale so that the (less efficient) monopolist would also be the monopolist of the $\mathrm{BC}$ segment and reap monopoly profits from the standalone $B C$ service or from the through service to the other points. To achieve this outcome, the monopolist could understate its marginal costs of production of the complementary component (BC service) and then employ the ECPR criterion to levy an exclusionary access fee vis-a-vis the rival.

As a second case, we alter our earlier assumption about the monopolist's behavior in the bottleneck market. We assume that the monopolist is constrained by regulation to earn zero excess profits in the bottleneck market. If, however, the regulator cannot observe the monopolist's costs perfectly, then the monopolist can increase its aggregate profits by claiming that some of its costs of production of the complementary component should be treated (for regulatory purposes) as costs of production of the bottleneck services. ${ }^{20}$ To the extent that the monopolist succeeds in this "cre-

20 This is a well-known possibility and was one of the major arguments for separating regulated monopoly local telephone service from other complementary services. See, for example, Roger G. Noll \& Bruce M. Owen, The Anticompetitive Uses of Regulation: United States v. AT\& $T$, in THE ANTTTRUST REVOLUTION: THE ROLE OF ECONOMICS 328 (John E. Kwoka \& Lawrence J. White eds., 1994); Timothy J. Brennan, Why 
ative accounting" for some of the marginal costs of production of the complementary component, these apparently lower marginal costs would justify a higher ECPR access fee. This higher access fee will again deter some efficient rivals-i.e., those with marginal production cost levels that are less than the monopolist's true marginal costs of production of the complementary component but greater than the remaining marginal costs that the monopolist still attributes to the production of the complementary component.21

\section{Conclusion}

The efficient component pricing rule for access pricing has a seductive logic: It appears to insure that only efficient production of a complementary component (to a monopoly bottleneck service) will occur. The ECPR holds as a first-best principle, however, only under a stringent set of assumptions.

Only empirical observation can ascertain whether these assumptions are closely enough approximated in reality that the ECPR is a reasonable basis for policy. Our professional judgment is that real-world conditions are often likely to diverge importantly from the necessary assumptions. We are most concerned about the assumption that the monopolist's pricing of the complementary component is driven by marginal cost (or Ramsey) principles. If, instead, the monopolist's price reflects the exercise of market power, then the ECPR will protect that market power and prevent consumers from benefiting from the price competition that a rival (entrant) could bring. We show that there are quite reasonable circumstances under which the presence of even a less efficient rival would bring about a positive net social welfare

Regulated Firms Should Be Kept Out of Unregulated Markets: Understanding the Divestiture in United States v. AT\&T, 32 ANTrTRUST BuLL. 741 (1987); and Timothy J. Brennan, Cross-Subsidization and Cost Misallocation by Regulated Monopolists, 2 J. REG. ECoN. 37 (1990).

21 Though this incentive for cost shifting (which is, in essence, regulatory evasion) is not dependent on the presence of the ECPR, the ECPR may well add the distorting element of the exclusion of an efficient rival. 
change. We also explore the consequences of the loosening of some of the other assumptions.

In sum, in real-world settings policy makers should be wary of blind devotion to the ECPR. It has dangers as well as benefits, and the real-world settings may well be ones in which the dangers outweigh the benefits. 
576 : The antitrust bulletin

\section{APPENDIX A}

In this appendix, we show how the net social gain can be expressed in terms of $t, \theta$, and $e$, and how $t^{*}$ can subsequently be determined. We assume that the incumbent has marginal costs of $c$ and that the rival has marginal costs of $c+t$.

If the incumbent can exercise market power and act as a monopolist, its price $\left(P_{M}\right)$ is

$$
P_{M}=c \cdot e /(e-1) \text {. }
$$

If, in the presence of the rival, the monopolist practices limit pricing, the price $\left(\mathrm{PJ}_{J}\right)$ at which both firms will sell $\left(\mathrm{P}_{J}=\mathrm{P}_{\mathrm{M}}=\mathrm{P}_{\mathrm{R}}\right)$ is

$$
P_{J}=c+t \text {. }
$$

The consumers' surplus "triangle" gain from this switch from monopoly to limit pricing is

$$
\begin{aligned}
1 / 2(\Delta Q)(\Delta P) & =1 / 2\left(Q_{J}-Q_{M}\right) \cdot\left(P_{M}-P_{J}\right) \\
& =e Q_{J}(\Delta P)^{2 /\left(2 P_{J}\right)} \\
& =e Q_{J}[c /(e-1)-t]^{2 /[2(c+t)] .}
\end{aligned}
$$

The producers' surplus "rectangle" gain is

$$
\begin{aligned}
t \cdot(\Delta Q) & =t \cdot\left(Q_{J}-Q_{M}\right) \\
& =\operatorname{te}(\Delta P) Q_{J} / P_{J} \\
& =t e Q_{J}[c /(e-1)-t] /[2(c+t)]
\end{aligned}
$$

Finally, the production inefficiency loss "rectangle" is

$$
t \theta Q_{J} \text {. }
$$

If the last expression is subtracted from the sum of the preceding two expressions, the net social gain that results from entry and limit pricing is

$$
\mathrm{QJ}\left[e\left\{[c /(e-1)-t]^{2}+t[c /(e-1)-t]\right\} /[2(c+t)]-t \theta\right] .
$$

If we normalize by setting $c=1$, we find that this expression is positive if and only if 


$$
t<t *=\frac{\theta-\sqrt{\theta^{2}+\frac{e^{2}+2 \theta e}{(e-1)^{2}}}}{-(e+2 \theta)}
$$

It is this expression that is the basis for the values in table 1. 
578 : The antitrust bulletin

\section{APPENDIX B}

In this appendix, we provide the solution to the simple Cournot game and the subsequent determination of $t^{*}$, where the incumbent has marginal costs of $c$, the rival has marginal costs of $c+t$, and the inverse demand for the service is linear, $P=a-b Q$, expressing the relationship between price $(P)$ and quantity (Q). Quantity, in turn, is the sum of the incumbent's production (QI) and the rival's production $\left(Q_{R}\right)$; the price at which they sell jointly is $P_{J}$.

The incumbent's profits are

$$
\Pi_{I}=\left[a-b\left(Q_{I}+Q_{R}\right)\right] \cdot Q_{I}-c Q_{I} \text {. }
$$

The rival's profits are

$$
\Pi_{R}=\left[a-b\left(Q_{I}+Q_{R}\right)\right] \cdot Q_{R}-(c+t) Q_{R} .
$$

The non-cooperative equilibrium of the quantity setting (Cournot) game is

$$
\begin{gathered}
Q_{I}=(a-c+t) /(3 b), Q_{R}=(a-c-2 t) /(3 b), \\
Q_{J}=Q_{I}+Q_{R}=[2(a-c)-t] /(3 b), \\
P_{J}=(a+2 c+t) / 3 .
\end{gathered}
$$

Given the quantities determined at the equilibrium, the market share of the rival is

$$
\theta=Q_{R} / Q_{J}=[a-c-2 t] /[2(a-c)-t] .
$$

Since the pure monopoly equilibrium for the incumbent is

$$
Q_{M}=(a-c) /(2 b), P_{M}=(a+c) / 2,
$$

the consumers' surplus "triangle" gain from the switch from the monopoly to Cournot duopoly is

$$
1 / 2(\Delta Q)(\Delta P)=1 / 2\left(Q_{J}-Q_{M}\right)\left(P_{M}-P_{J}\right)=(a-c-2 t)^{2 /(72 b)} .
$$

The producers' surplus "rectangle" gain from the switch is

$$
\left(Q_{J}-Q_{M}\right)\left(P_{J}-c\right)=[a-c-2 t][a-c+t] /(18 b) \text {. }
$$


Finally, the production inefficiency loss "rectangle" attributable to the rival's output is

$$
t Q_{R}=t(a-c-2 t) /(3 b) .
$$

If the last expression is subtracted from the sum of the preceding two expressions, the net social gain that results from entry under Cournot behavior is

$$
[a-c-2 t][5(a-c)-22 t] /(72 b) \text {. }
$$

This expression is positive if and only if both bracketed terms are positive (or both are negative). The economically relevant case requires

$$
5(a-c)-22 t>0
$$

or, equivalently, .

$$
\mathrm{t}<\mathrm{t}^{*}=5(\mathrm{a}-\mathrm{c}) / 22 \text {. }
$$

The elasticity of demand at the Coumot equilibrium is

$$
e=(\Delta Q / \Delta P) /\left(Q_{J} / P_{J}\right)=[a+2 c+t] /[2(a-c)-t]
$$

If we normalize by setting $c=1$, this last expression can be solved for $a$ in terms of $e$ and $t$, and this result can then be used to solve for $t^{*}$ in terms of the elasticity e:

$$
t^{*}=5 /(13 e-9) \text {. }
$$

It is this expression that provides the basis for the values in table 2 . 